is no generally applicable solution to problems of this kind, and each of them must be considered individually on the same level as the malariological and entomological investigations that are now regarded as an essential part of malaria eradication programmes. Population distribution, settlement patterns, types of housing, farming practices, communications, water supplies and other relevant factors vary so much from one area to another that generalization is impossible. Geographical reconnaissance, as it now exists in eradication programmes, does not cover every aspect of population movement. Where necessary, it will have to be expanded to collect much wider information on the factors described, in order to understand the whole complex of physical environment, malaria parasites, vectors and people. It may then be possible to evolve the correct technique applicable to each individual local situation. The inclusion of professional geographers in some malaria teams for full-time work at the outset of a programme would be valuable; when they had collected the required information, it would not be necessary to retain their services, since the geographical data could afterwards be kept up-to-date by a specially trained sanitarian. There is also a need for detailed individual study of every migration problem arising in the course of malaria eradication in tropical Africa.

\title{
POLLUTION FROM REFUSE TIPS
}

$\mathrm{T}$ WO problems associated with modern living conditions are the disposal of house refuse and the reclamation of land from which chalk, gravel or other material has been renaoved. The possibility of solving these two problems at one blow by tipping the refuse into worked-out pits is attractive, provided that this can be done safely and without nuisance.

One of the dangers of this procedure, which is widely practised, is that water supplies may be contaminated by drainage from the refuse. To study this problem the Minister of Housing and Local Government, in 1953, appointed a technical committee to supervise experiments on the tipping of refuse, with special reference to the pollution of underground water. These experiments were carried out in the Laboratory of the Government Chemist, and the report on the results has recently been published, together with the conclusions and recommendations of the Committee*.

Two series of experiments were made : one on refuse tipped dry and the other on refuse tipped into water. The vo ume and composition of the liquid draining from the pits were determined, and the purification effected by passing this liquid through sand and gravel was studied.

The Committee points out that the matter is complex, and is careful to avoid over-simplified

* Ministry of Housing and Locas Government. Pollution of Water by Tipped Refuse. Report of the Technical Committee on the Experimental Disposal of House Refuse in Wet and Dry Pits. (H.M.S.O. London, 1961.) 78 . conclusions in its report. It appears, however, that the results of the experiments are reasonably encouraging and that, provided certain precautions are taken, the practice of tipping refuse may safely be continued and even extended. Although \& highly polluting liquid is produced by percolation of rainwater through refuse, the amount of organic pollution falls off relatively rapidly with time. In addition, when refuse is tipped dry, a considerable amount of rain has to fall on it before any drainage water is produced. Thus if the amount of rainfall reaching the refuse can be reduced by covering the material with an impermeable layer as soon as possible after tipping, the total load of pollution discharged from the pit will be decreased. This is one of the reasons why the Committee considers that, under comparable conditions, dry tipping is less likely than wet tipping to affect water supplies adversely. It does not, however, rule out the use of wet sites, for the experiments showed that considerable purification of the liquid can be effected by percolation of the water from the pit through the surrounding ground. One suggestion of the Committee is that refuse might be tipped first into a dry pit, where initial decomposition would occur, and that after about two years it should be transferred to a wet tip, leaving the first site to be used again.

It is not claimed that the experiments described were exhaustive, and several lines of investigation remain to be followed.
NORA H. JOHNSON

\section{TOXICOLOGY OF PENICILLIUM ISLANDICUM}

$\mathrm{T}$ OXICOLOGICAL research into the methanol extract of the fum.gus $P$, islandicum has been carried out since the spring of 1954 , with collaboration in the fields of mycology, chomistry and medicine. In five biological testings, methanol extract prepared from the fungus mat of $U b, U c$ or $E a$ strains was administered in the form of oil solution or water suspension to 150 mice and 10 rats, orally or subcutaneously, to observe pathological changes; in chemical testings, chemical fractionations of the methanol extract were carried out.

Biological data observed a few days after a singlo or several doses of the methanol extract had been administered have been summarized by $\mathrm{K}$. Uraguchi,
T. Tatsuno, M. Tsukioka, Y. Sakai, F. Sakai, Y. Kobayahi, M. Saito, M. Enomoto and M. Miyake of the Departments of Pharmacology and Pathology, Faculty of Medicine, University of Tokyo, Bunkyoku, Tokyo, Japan (Jap. J. Exp. Med., 31, No. 1; 1961), as follows: Acute symptoms of poisoning are developed in mice and rats, but their life-time is prolonged with reduced doses. Poison damages show that abnormal function of the liver is detectable by the bromsulphthalein retention test, and autopsy shows, in most of the liver, centrolobular necrosis, fatty metamorphosis of liver cells and interconnexion between the necrotic areas with subsequent collapse; in part of the liver there is vacuolation of liver cells 